\title{
Eficácia de Imazethapyr e Chlorimuron-Ethyl em APLiCAÇões de Pré-Semeadura da Cultura da Soja ${ }^{1}$
}

\author{
Efficacy of Imazethapyr and Chlorimuron-Ethyl in Pre-Sowing Applications on Soybean Crop
}

PROCÓPIO, S.O. ${ }^{2}$, MENEZES, C.C.E. ${ }^{3}$, PIRES, F.R. ${ }^{2}$, BARROSO, A.L.L. ${ }^{2}$, CARGNELUTTI FILHO, A. ${ }^{4}$, RUDOVALHO, M.C. ${ }^{5}$, MORAES, R.V. ${ }^{5}$, SILVA, M.V.V. ${ }^{5}$ e CAETANO, J.O. ${ }^{6}$

\begin{abstract}
RESUMO - O trabalho teve como objetivo avaliar a ação dos herbicidas imazethapyr e chlorimuron-ethyl em aplicações de pré-semeadura da cultura da soja, visando o controle das plantas daninhas presentes antes da semeadura e a redução na emergência de plantas daninhas durante o ciclo da cultura. O experimento foi conduzido a campo, em área de produção de soja em sistema de plantio direto. O delineamento experimental utilizado foi o de blocos casualizados, com quatro repetições, em esquema fatorial $(4 \times 4+1)$, sendo quatro tratamentos herbicidas Iglyphosate $\left(1,62 \mathrm{~kg} \mathrm{ha}^{-1}\right)$; glyphosate $\left(1,62 \mathrm{~kg} \mathrm{ha}^{-1}\right)+$ imazethapyr (100 $\left.\mathrm{g} \mathrm{ha}^{-1}\right)$; glyphosate $\left(1,62 \mathrm{~kg} \mathrm{ha}^{-1}\right)+$ chlorimuron-ethyl $\left(10 \mathrm{~g} \mathrm{ha}^{-1}\right)$; glyphosate $\left(1,62 \mathrm{~kg} \mathrm{ha}^{-1}\right)+$ chlorimuron-ethyl $\left.\left(20 \mathrm{~g} \mathrm{ha}^{-1}\right)\right]$ e quatro intervalos entre a aplicação dos herbicidas e a semeadura da soja $(0,1,3 \mathrm{e}$ 7 dias), mais uma testemunha não-dessecada. A adição dos herbicidas imazethapyr ( $\left.100 \mathrm{~g} \mathrm{ha}^{-1}\right)$ e chlorimuron-ethyl (10 ou $20 \mathrm{~g} \mathrm{ha}^{-1}$ ) junto ao glyphosate não melhorou o controle e também não diminuiu a rebrota posterior das plantas daninhas Digitaria insularis, Tridax procumbens e Leptochloa filiformis. Três dias antes da semeadura da soja foi o intervalo mínimo para que o controle dessas três espécies de plantas daninhas não fosse prejudicado pela operação de semeadura mecânica. Constatou-se que os tratamentos herbicidas não afetaram o número de plantas emergidas das espécies Sida santaremnensis, Digitaria insularis, Eleusine indica, Chamaesyce hirta, Bidens pilosa e Senna obtusifolia. Apenas para a espécie Althernantela tenella foi verificado que a adição de imazethapyr ou de chlorimuron-ethyl junto ao glyphosate reduziu a emergência dessa planta daninha na área, mostrando eficiência em pré-emergência. Todos os tratamentos herbicidas aplicados em pré-semeadura proporcionaram maior produtividade da cultura da soja em relação à testemunha não-dessecada, mas o incremento dos herbicidas imazethapyr e chlorimuron-ethyl ao glyphosate não resultou em aumento de produtividade da soja.
\end{abstract}

Palavras-chave: herbicida, planta daninha, Glycine max, glyphosate.

ABSTRACT - This work was carried out to evaluate the efficacy of the herbicides imazethapyr and chlorimuron-ethyl under pre-sowing conditions in soybean crop. Weed control before sowing and emergence reduction during the crop season were evaluated. The experiment was established in the field soybean had been cultivated, under no tillage, arranged in a randomized block design in a factorial design $(4 \times 4)+1$. Four herbicide treatments Iglyphosate (1.62 kg ha-1); glyphosate (1.62 $\left.\mathrm{kg} \mathrm{ha}^{-1}\right)+$ imazethapyr (100 $\left.\mathrm{g} \mathrm{ha}^{-1}\right)$; glyphosate (1.62 $\left.\mathrm{kg} \mathrm{ha}^{-1}\right)+$ chlorimuron-ethyl $\left(10 \mathrm{~g} \mathrm{ha}^{-1}\right)$; glyphosate $\left(1.62 \mathrm{~kg} \mathrm{ha}^{-1}\right)+$ chlorimuron-ethyl $\left.\left(20 \mathrm{~g} \mathrm{ha}^{-1}\right)\right]$ were combined with four application intervals between herbicide application and sowing time (0, 1, 3 and 7 days). The variety MG/BR 46 (Conquista), with rows spaced $0.50 \mathrm{~m}$ was also used as control, with no herbicide application. The addition of the herbicides [imazethapyr (100 $\left.\mathrm{g} \mathrm{ha}^{-1}\right)$ and chlorimuron-ethyl (10 ou $20 \mathrm{~g} \mathrm{ha}^{-1}$ )] to glyphosate did not improve weed control nor decreased late re-growth of the following species: Digitaria insularis, Tridax procumbens and Leptochloa filiformis. Three days was the minimum interval in which the three species were not injured by the mechanical sowing process.

Recebido para publicação em 15.12.2005 e na forma revisada em 4.8.2006.

2 Professor da Faculdade de Agronomia da Universidade de Rio Verde - FESURV. ${ }^{3}$ Engenheiro-Agrônomo da Cooperativa Agroindustrial dos Produtores Rurais do Sudoeste Goiano, <cmenezes@ fesurv.br>. ${ }^{4}$ Professor da UNESP/Jaboticabal. ${ }^{5}$ Discente do curso de Agronomia da FESURV; ${ }^{6}$ Mestrando do Programa de Pós-Graduação em Produção Vegetal da FESURV.

Planta Daninha, Viçosa-MG, v. 24, n. 3, p. 467-473, 2006 
The herbicide treatments did not affect the number of emerged plants of the following species: Sida santaremnensis, Digitaria insularis, Eleusine indica, Chamaesyce hirta, Bidens pilosa e Senna obtusifolia. Only Althernantela tenella had its emergence rate decreased by herbicide addition to glyphosate, showing pre-sowing efficiency. All the herbicide treatments during pre-sowing increased soybean yield, compared to the control. Herbicide addition to glyphosate did not result in increasing yield.

Keywords: $\quad$ herbicide, weed, Glycine max, glyphosate.

\section{INTRODUÇÃO}

O sistema de plantio direto realizado no cerrado brasileiro tem como operação básica para seu sucesso a dessecação ou manejo químico, que consiste da aplicação de um herbicida, ou de uma mistura de dois ou mais, ou mesmo de duas aplicações seqüenciais do mesmo ou de diferentes herbicidas, antes da semeadura das culturas. Roman \& Didonet (1990) afirmam que a utilização de herbicidas dessecantes no sistema de plantio direto deve ter, no mínimo, igual eficiência quando comparado ao preparo do solo no controle das plantas daninhas presentes na área.

Com o avanço da utilização dessa técnica surgiram novas alternativas, como a associação de herbicidas residuais junto aos nãoseletivos. Segundo Vanlieshout \& Loux (2000), o herbicida glyphosate freqüentemente é aplicado em associação com herbicidas de ação de solo para controle de plantas daninhas em sistemas de plantio direto. Conforme Carvalho et al. (2000), a associação de herbicidas que possuam efeito residual no solo com herbicidas dessecantes apresenta-se como uma alternativa para reduzir as infestações de plantas daninhas, podendo proporcionar redução no custo de controle. Além desse benefício, a prática de inclusão de herbicidas residuais junto às aplicações de manejo resulta em menor exposição do aplicador, menor compactação dos solos e, possivelmente, melhor controle das plantas daninhas no início do seu estabelecimento (Valente \& Cavazzana, 2000). De acordo com Corrigan \& Harvey (2000), em situações em que o nivel de competição entre a cultura da soja resistente a glyphosate e as plantas daninhas é severo e não haja possibilidade de assegurar a época precisa de aplicação do glyphosate, a utilização de herbicidas com atividade residual no solo pode ser benéfica.
Em trabalho realizado por Roman (2002) observou-se controle de 95\% de Bidens pilosa aos 45 dias após a aplicação da mistura de glyphosate (720 $\mathrm{g} \mathrm{ha}^{-1}$ ) com chlorimuron-ethyl (10 $\mathrm{g} \mathrm{ha}^{-1}$ ), em pré-semeadura da cultura da soja. Valente \& Cavazzana (2000) classificaram como excelente o controle da sementeira de Bidens pilosa com a aplicação em pré-semeadura de glyphosate mais chlorimuron-ethyl. Carvalho \& Cavazzana (2000) mostraram que o chlorimuron-ethyl (10 e $20 \mathrm{~g} \mathrm{ha}^{-1}$ ), aplicado juntamente com o glyphosate no manejo, proporcionou ao tratamento um efeito residual significativo para Bidens pilosa, reduzindo a infestação de plantas daninhas durante o ciclo da cultura da soja, porém não tendo efeito significativo para Commelina benghalensis.

Além de proporcionar um período de impedimento da emergência das plantas daninhas, a associação de herbicidas residuais pode também melhorar a eficiência do glyphosate sobre plantas que apresentem certo grau de tolerância. Vangessel et al. (2001) verificaram que, comparada à aplicação isolada de glyphosate, a mistura em tanque de glyphosate, clomazone e imazethapyr promoveu melhor controle de Chenopodium album, Panicum dichotomiflorum e Ambrosia artemisiifolia. Vidrine et al. (2002), por sua vez, observaram que a adição do herbicida chlorimuron-ethyl ao glyphosate resultou em baixos incrementos do controle de Ipomoea hederacea (5\%), enquanto para o controle de Sesbania exaltata o aumento foi de $12 \%$. Ainda avaliando a mistura de herbicidas para dessecação, o trabalho realizado por Norsworthy \& Grey (2004) mostra que a adição de chlorimuron-ethyl ao glyphosate elevou o controle das espécies Ipomoea hederacea e Ipomoea purpurea. Monquero et al. (2001) constataram que a adição de chlorimuron-ethyl ao glyphosate, 
em aplicação de manejo, promoveu efeito sinergístico no controle de Amaranthus hybridus e Richardia brasiliensis.

Dentro desse cenário, o trabalho teve como objetivo avaliar a ação dos herbicidas imazethapyr e chlorimuron-ethyl, em aplicações de pré-semeadura da cultura da soja, visando o controle das plantas daninhas presentes antes da semeadura e a redução na emergência destas plantas durante o ciclo da cultura.

\section{MATERIAL E MÉTODOS}

O experimento foi conduzido a campo, localizado no município de Rio Verde-GO, na safra 2003/2004, em área de produção de soja sob sistema de plantio direto.

O delineamento experimental utilizado foi o de blocos casualizados, em esquema fatorial $(4 \times 4+1)$, sendo quatro tratamentos herbicidas [glyphosate $\left(1,62 \mathrm{~kg} \mathrm{ha}^{-1}\right)$; glyphosate $\left(1,62 \mathrm{~kg} \mathrm{ha}^{-1}\right)+$ imazethapyr (100 $\left.\mathrm{g} \mathrm{ha}^{-1}\right)$; glyphosate $\left(1,62 \mathrm{~kg} \mathrm{ha}^{-1}\right)+$ chlorimuron-ethyl (10 $\left.\mathrm{g} \mathrm{ha}^{-1}\right)$; glyphosate $\left(1,62 \mathrm{~kg} \mathrm{ha}^{-1}\right)+$ chlorimuron-ethyl $\left.\left(20 \mathrm{~g} \mathrm{ha}^{-1}\right)\right]$ e quatro intervalos entre a aplicação dos herbicidas e a semeadura da soja (0, 1, 3 e 7 dias), mais uma testemunha não-dessecada. Foram realizadas quatro repetições.

Os herbicidas foram aplicados em présemeadura da cultura da soja (dessecação), sendo empregado para sua execução um pulverizador costal pressurizado com $\mathrm{CO}_{2}$, acoplado com barra, contendo quatro pontas de pulverização do tipo leque XR 110.02. $\mathrm{O}$ volume de calda utilizado foi de $150 \mathrm{~L} \mathrm{ha}^{-1}$. As plantas daninhas predominantes na área experimental no momento da realização das aplicações em pré-semeadura eram capim-amargoso (Digitaria insularis), erva-detouro (Tridax procumbens) e capim-mimoso (Leptochloa filiformis), todas em fase reprodutiva.

O cultivar de soja semeado foi o Conquista, sendo utilizado o espaçamento de $0,50 \mathrm{~m}$. A semeadura foi realizada por meio de uma semeadora pneumática, regulada para liberar 18 sementes por metro. Junto à semeadura foi também realizada adubação de base, com $400 \mathrm{~kg} \mathrm{ha}^{-1}$ da fórmula 02-20-18. As parcelas experimentais possuíam $12 \mathrm{~m}^{2}(4 \times 3 \mathrm{~m})$, sendo a área útil de avaliação de $6 \mathrm{~m}^{2}$.

Foram realizadas as seguintes avaliações: controle de plantas daninhas aos 21 dias após a semeadura (DAS), utilizando-se escala percentual de 0 a $100 \%$, correspondentes a nenhum controle e morte das plantas, respectivamente; rebrota das plantas daninhas aos 33 DAS, utilizando-se também escala percentual de 0 a 100\%, significando nenhuma rebrota e rebrota total das plantas, respectivamente; porcentagem de cobertura do solo pelas plantas daninhas aos 34 DAS; e produtividade de grãos. Cinco dias após a realização da avaliação da cobertura das plantas daninhas na área, foi aplicada em pós-emergência a mistura herbicida pré-formulada de fomesafen + fluazifop-p-butyl $\left(250+250 \mathrm{~g} \mathrm{ha}^{-1}\right)$ em todas as parcelas.

Após a coleta e tabulação dos dados, estes foram submetidos à análise de variância, sendo as médias das variáveis significativas comparadas pelo teste de Tukey a 5\% de significância.

\section{RESULTADOS E DISCUSSÃO}

Não se observou interação entre os efeitos dos tratamentos herbicidas e do intervalo entre a aplicação e a semeadura da soja, em relação ao controle das plantas daninhas $D$. insularis, $T$. procumbens e L. filiformis. Também não se constataram diferenças entre os tratamentos herbicidas aplicados em pré-semeadura e o controle dessas plantas daninhas, mostrando que a adição dos herbicidas imazethapyr (100 $\mathrm{g} \mathrm{ha}^{-1}$ ) e chlorimuron-ethyl (10 ou $20 \mathrm{~g} \mathrm{ha}^{-1}$ ) junto ao glyphosate não melhorou o controle das plantas daninhas, inclusive o de T. procumbens, espécie para a qual o glyphosate não apresenta controle satisfatório (Tabela 1). Esses resultados elucidam que imazethapyr e chlorimuron-ethyl não são alternativas eficazes para substituição do herbicida 2,4-D em aplicações de pré-semeadura, visando o controle de T. procumbens. Por outro lado, esses dois herbicidas inibidores da ALS não prejudicaram a ação do glyphosate sobre as gramineas $D$. insularis e L. filiformis, não havendo interação antagonística, o que concorda com o observado por Vidrine et al. (2002) em relação ao controle de Echinocloa crus-galli, para o qual a mistura de glyphosate com 
chlorimuron-ethyl também não mostrou efeito antagonístico.

Aproximadamente três dias antes da semeadura da soja foi o intervalo mínimo para que o controle das três espécies de plantas daninhas não fosse prejudicado pela operação de semeadura mecânica, independentemente do tratamento herbicida aplicado (Figura 1). Esses resultados corroboram os encontrados por Procópio et al. (2006), que observaram controle satisfatório e impedimento de rebrota de $D$. insularis e $L$. filiformis quando o glyphosate foi aplicado cinco dias antes da semeadura da soja.

O nível de rebrota das plantas daninhas não foi afetado pelos tratamentos herbicidas, variando de 12 a $21 \%$ para $D$. insularis, de 10 a $20 \%$ para $L$. filiformis e de $100 \%$ para as plantas de $T$. procumbens (Tabela 2), sendo estes valores médias dos quatro intervalos entre a aplicação e a semeadura. Quando a semeadura foi realizada no mesmo dia da dessecação, a rebrota observada nas plantas de $D$. insularis e $L$. filiformis foi maior que $50 \%$ (Figura 2).

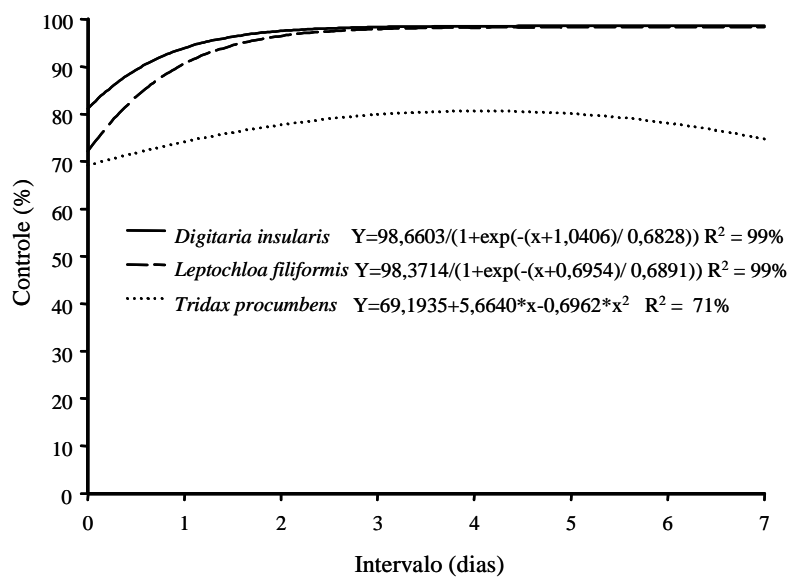

Figura 1 - Controle de plantas daninhas após aplicação de diferentes tratamentos herbicidas em dessecação, em função de diferentes intervalos entre a aplicação dos herbicidas e a semeadura da soja, avaliado aos 21 dias após a semeadura. Rio Verde-GO.

Novamente, para evitar a rebrota de $D$. insularis e $L$. filiformis, aproximadamente três dias foi o intervalo mínimo entre a aplicação dos herbicidas e a semeadura mecânica

Tabela 1 - Porcentagem de controle de plantas daninhas com diferentes tratamentos herbicidas aplicados em pré-semeadura (dessecação) da cultura da soja, avaliada aos 21dias após a semeadura. Rio Verde-GO

\begin{tabular}{|l|c|c|c|}
\hline \multirow{2}{*}{ Tratamento herbicida $^{1 /}$} & Digitaria insularis & Leptochloa filiformis & Tridax procumbens \\
\cline { 2 - 4 } & & \multicolumn{3}{|c|}{ Controle $(\%)$} \\
\hline glyphosate $\left(1,62 \mathrm{~kg} \mathrm{ha}^{-1}\right)$ & 94 & 91 & 71 \\
\hline glyphosate $\left(1,62 \mathrm{~kg} \mathrm{ha}^{-1}\right)+$ imazethapyr $\left(100 \mathrm{~g} \mathrm{ha}^{-1}\right)$ & 93 & 89 & 74 \\
\hline glyphosate $\left(1,62 \mathrm{~kg} \mathrm{ha}^{-1}\right)+$ chlorimuron-ethyl $\left(10 \mathrm{~g} \mathrm{ha}^{-1}\right)$ & 93 & 89 & 79 \\
\hline glyphosate $\left(1,62 \mathrm{~kg} \mathrm{ha}^{-1}\right)+$ chlorimuron-ethyl $\left(20 \mathrm{~g} \mathrm{ha}^{-1}\right)$ & 93 & 91 & 73 \\
\hline Média geral & 93 & 90 & 74 \\
\hline
\end{tabular}

1’ Média de tratamentos não diferem pelo teste $\mathrm{F}$ a $5 \%$ de probabilidade.

Tabela 2 - Porcentagem de rebrota de plantas daninhas após aplicação de diferentes tratamentos herbicidas em pré-semeadura (dessecação) na cultura da soja, avaliada aos 33 dias após a semeadura. Rio Verde-GO

\begin{tabular}{|c|c|c|c|}
\hline \multirow{2}{*}{ Tratamento herbicida ${ }^{\underline{1}}$} & Digitaria insularis & Leptochloa filiformis & Tridax procumbens \\
\hline & \multicolumn{3}{|c|}{ Controle $(\%)$} \\
\hline glyphosate $\left(1,62 \mathrm{~kg} \mathrm{ha}^{-1}\right)$ & 21 & 20 & 100 \\
\hline glyphosate $\left(1,62 \mathrm{~kg} \mathrm{ha}^{-1}\right)+$ imazethapyr $\left(100 \mathrm{~g} \mathrm{ha}^{-1}\right)$ & 21 & 19 & 100 \\
\hline glyphosate $\left(1,62 \mathrm{~kg} \mathrm{ha}^{-1}\right)+$ chlorimuron-ethyl $\left(10 \mathrm{~g} \mathrm{ha}^{-1}\right)$ & 14 & 10 & 100 \\
\hline glyphosate $\left(1,62 \mathrm{~kg} \mathrm{ha}^{-1}\right)+$ chlorimuron-ethyl $\left(20 \mathrm{~g} \mathrm{ha}^{-1}\right)$ & 12 & 10 & 100 \\
\hline Média geral & 17 & 15 & 100 \\
\hline
\end{tabular}

1/ Média de tratamentos não diferem pelo teste $\mathrm{F}$ a $5 \%$ de probabilidade. 


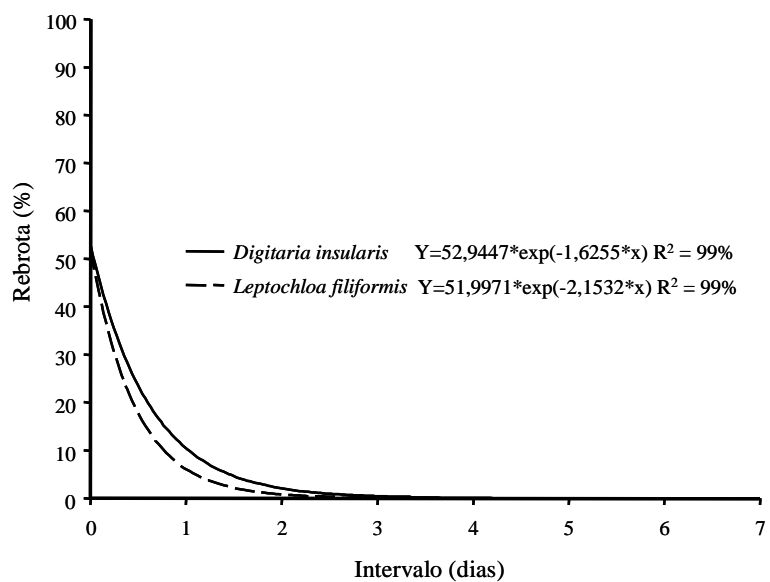

Figura 2 - Porcentagem de rebrota de duas espécies de plantas daninhas após aplicação de diferentes tratamentos herbicidas em dessecação, em função de diferentes intervalos entre a aplicação dos herbicidas e a semeadura da soja, avaliada aos 33 dias após a semeadura. Rio Verde-GO.

da soja (Figura 2). Isso demonstra que possivelmente a adição de imazethapyr ou chlorimuron-ethyl não acelerou nem retardou a translocação do glyphosate para o sistema radicular dessas espécies de plantas daninhas gramíneas. A partir desses resultados, constata-se que, quando há na área a ser dessecada plantas daninhas de propagação vegetativa, a técnica denominada de "aplique e plante", ou seja, dessecar e semear no mesmo dia ou, no máximo, um dia após a aplicação dos herbicidas, pode trazer problemas de rebrote dessas espécies durante o ciclo de desenvolvimento das culturas. Esse problema parece ocorrer em razão da lenta translocação do princípio ativo até seu sítio de ação (plastídios) nas raízes. Essa constatação foi feita por Koger \& Reddy (2005), os quais observaram que, do total absorvido de glyphosate por plantas de Ipomoea lacunosa, 0,4 e 25,0\% haviam sido translocados da região de absorção 1 e 192 horas após a aplicação, respectivamente.

Em relação à emergência de plantas daninhas durante a fase vegetativa da cultura da soja, avaliada com base na porcentagem de solo coberto pelas plantas daninhas na parcela, constatou-se que os tratamentos herbicidas não afetaram o número de plantas emergidas das espécies Sida santaremnensis, Digitaria insularis, Eleusine indica, Chamaesyce hirta, Bidens pilosa e Senna obtusifolia (Tabelas 3 e 4). Apenas para a espécie Althernantela tenella foi verificado que a adição de imazethapyr (100 $\mathrm{g} \mathrm{ha}^{-1}$ ) ou de chlorimuron-ethyl (10 ou $20 \mathrm{~g} \mathrm{ha}^{-1}$ ) junto ao glyphosate reduziu a emergência dessa planta daninha na área, mostrando, para essa espécie, eficiência em pré-emergência (Tabela 4). Resultados de pesquisa mostram diminuição na emergência de plantas daninhas quando se aplicaram, junto à dessecação, herbicidas de ação de solo como imazethapyr ou chlorimuron-ethyl (Carvalho et al., 2000; Valente \& Cavazzana, 2000; Roman, 2002). Carvalho \& Cavazzana (2000) afirmaram que o chlorimuron-ethyl (10 e $20 \mathrm{~g} \mathrm{ha}^{-1}$ ), aplicado juntamente com o glyphosate no manejo, proporcionou ao tratamento um efeito residual significativo para Bidens pilosa, reduzindo a infestação dessa planta daninha durante o ciclo da cultura da soja, porém não tendo efeito significativo para Commelina benghalensis.

A provável causa para a baixa eficiência em pré-emergência dos herbicidas de ação residual foi a alta densidade de plantas daninhas na área experimental no momento das

Tabela 3 - Porcentagem de cobertura do solo por plantas daninhas após aplicação de diferentes tratamentos herbicidas em présemeadura (dessecação) na cultura da soja, avaliada aos 34 dias após a semeadura. Rio Verde-GO

\begin{tabular}{|c|c|c|c|}
\hline \multirow{2}{*}{ Tratamento herbicida ${ }^{1 /}$} & Sida santaremnensis & Digitaria insularis & Eleusine indica \\
\hline & \multicolumn{3}{|c|}{ Cobertura do solo $(\%)$} \\
\hline glyphosate $\left(1,62 \mathrm{~kg} \mathrm{ha}^{-1}\right)$ & 3 & 10 & 7 \\
\hline glyphosate $\left(1,62 \mathrm{~kg} \mathrm{ha}^{-1}\right)+$ imazethapyr $\left(100 \mathrm{~g} \mathrm{ha}^{-1}\right)$ & 1 & "'m & ' \\
\hline glyphosate $\left(1,62 \mathrm{~kg} \mathrm{ha}^{-1}\right)+$ chlorimuron-ethyl $\left(10 \mathrm{~g} \mathrm{ha}^{-1}\right)$ & 4 & "'m & ' \\
\hline glyphosate $\left(1,62 \mathrm{~kg} \mathrm{ha}^{-1}\right)+$ chlorimuron-ethyl $\left(20 \mathrm{~g} \mathrm{ha}^{-1}\right)$ & 3 & 8 & 8 \\
\hline Média geral & 3 & 8 & 8 \\
\hline
\end{tabular}

${ }^{1 /}$ Média de tratamentos não diferem pelo teste $\mathrm{F}$ a $5 \%$ de probabilidade. 
Tabela 4 - Porcentagem de cobertura do solo por plantas daninhas após aplicação de diferentes tratamentos herbicidas em pré-semeadura (dessecação) na cultura da soja, avaliada aos 34 dias após a semeadura. Rio Verde-GO

\begin{tabular}{|c|c|c|c|c|}
\hline \multirow{2}{*}{ Tratamento herbicida } & Chamaesyce hirta & Bidens pilosa & Althernantela tenella & Senna obtusifolia \\
\hline & \multicolumn{4}{|c|}{ Cobertura do solo (\%) } \\
\hline glyphosate $\left(1,62 \mathrm{~kg} \mathrm{ha}^{-1}\right)$ & $13^{\mathrm{ns}}$ & $3^{\mathrm{ns}}$ & $13 \mathrm{a}$ & $2^{\mathrm{ns}}$ \\
\hline glyphosate $\left(1,62 \mathrm{~kg} \mathrm{ha}^{-1}\right)+$ imazethapyr $\left(100 \mathrm{~g} \mathrm{ha}^{-1}\right)$ & 9 & 2 & $6 \mathrm{~b}$ & 1 \\
\hline glyphosate $\left(1,62 \mathrm{~kg} \mathrm{ha}^{-1}\right)+$ chlorimuron-ethyl $\left(10 \mathrm{~g} \mathrm{ha}^{-1}\right)$ & 9 & 2 & $6 \mathrm{~b}$ & 2 \\
\hline glyphosate $\left(1,62 \mathrm{~kg} \mathrm{ha}^{-1}\right)+$ chlorimuron-ethyl $\left(20 \mathrm{~g} \mathrm{ha}^{-1}\right)$ & 6 & 1 & $1 \mathrm{~b}$ & 2 \\
\hline Média geral & 9 & 2 & 6 & 2 \\
\hline
\end{tabular}

Médias de tratamentos não seguidas de mesma letra diferem a 5\% de probabilidade pelo teste de Tukey.

${ }^{\mathrm{n} s}$ não-significativo pelo teste $\mathrm{F}$ a $5 \%$ de probabilidade.

dessecações, o que dificultou que a maior parte da calda herbicida atingisse a superfície do solo, ficando retida na folhagem das plantas daninhas e, conseqüentemente, reduzindo a ação desses herbicidas sobre a sementeira das plantas daninhas. Uma alternativa que poderia auxiliar na maior eficiência em pré-emergência dos herbicidas residuais aplicados junto à dessecação de manejo seria o aumento no volume de calda. O intervalo entre as aplicações dos herbicidas e a semeadura da soja não influenciou a emergência das plantas daninhas, independentemente do tratamento utilizado (Tabela 5). A baixa deposição dos herbicidas no solo pode ser novamente a causa desses resultados, pois espera-se que, quanto maior o tempo entre a aplicação dos herbicidas de ação de solo e a semeadura da cultura, maior a possibilidade de emergência de plantas daninhas na área antes do fechamento do dossel.

Todos os tratamentos herbicidas aplicados em pré-semeadura proporcionaram maior produtividade da cultura da soja em relação à testemunha não-dessecada (Tabela 6). A adição dos herbicidas imazethapyr e chlorimuronethyl ao glyphosate, nas doses testadas, não resultou em aumento de produtividade da soja. Vidrine et al. (2002) também não constataram aumento de produtividade da soja transgênica com a adição de chlorimuron-ethyl ao glyphosate.

A prática da adição de herbicidas de ação de solo junto à dessecação deve ser analisada com critério, pois, em casos de alta densidade

Tabela 6 - Produtividade de soja em área submetida a diferentes tratamentos herbicidas em pré-semeadura (dessecação). Rio Verde-GO

\begin{tabular}{|c|c|}
\hline Tratamento herbicida & \begin{tabular}{|c} 
Produtividade \\
$\left(\mathrm{kg} \mathrm{ha}^{-1}\right)$
\end{tabular} \\
\hline glyphosate $\left(1,62 \mathrm{~kg} \mathrm{ha}^{-1}\right)$ & $2.446 \mathrm{a}$ \\
\hline glyphosate $\left(1,62 \mathrm{~kg} \mathrm{ha}^{-1}\right)+$ imazethapyr $\left(100 \mathrm{~g} \mathrm{ha}^{-1}\right)$ & $2.455 \mathrm{a}$ \\
\hline glyphosate $\left(1,62 \mathrm{~kg} \mathrm{ha}^{-1}\right)+$ chlorimuron-ethyl $\left(10 \mathrm{~g} \mathrm{ha}^{-1}\right)$ & $2.389 \mathrm{a}$ \\
\hline glyphosate $\left(1,62 \mathrm{~kg} \mathrm{ha}^{-1}\right)+$ chlorimuron-ethyl $\left(20 \mathrm{~g} \mathrm{ha}^{-1}\right)$ & $2.290 \mathrm{a}$ \\
\hline Testemunha não-dessecada & $1.743 \mathrm{~b}$ \\
\hline Média geral & 2.265 \\
\hline
\end{tabular}

Médias de tratamentos não seguidas de mesma letra diferem a $5 \%$ de probabilidade pelo teste de Tukey.

Tabela 5 - Porcentagem de cobertura do solo por plantas daninhas após aplicação de diferentes tratamentos herbicidas em dessecação, em quatro intervalos de antecedência à semeadura da soja, avaliada aos 34 dias após a semeadura. Rio Verde-GO

\begin{tabular}{|c|c|c|c|c|c|c|c|}
\hline Intervalo $^{-1 /}$ & $\begin{array}{c}\text { Sida } \\
\text { santaremnensis }\end{array}$ & $\begin{array}{l}\text { Digitaria } \\
\text { insularis }\end{array}$ & $\begin{array}{c}\text { Eleusine } \\
\text { indica }\end{array}$ & $\begin{array}{c}\text { Chamaesyce } \\
\text { hirta }\end{array}$ & $\begin{array}{l}\text { Bidens } \\
\text { pilosa }\end{array}$ & $\begin{array}{c}\text { Althernantela } \\
\text { tenella }\end{array}$ & $\begin{array}{c}\text { Senna } \\
\text { obtusifolia }\end{array}$ \\
\hline (dias) & \multicolumn{7}{|c|}{ Cobertura do solo (\%) } \\
\hline 0 & 2 & 7 & 7 & 13 & 1 & 6 & 2 \\
\hline 1 & 3 & 8 & 6 & 8 & 2 & 6 & 1 \\
\hline 3 & 3 & 8 & 10 & 6 & 2 & 4 & 2 \\
\hline 7 & 3 & 9 & 10 & 9 & 2 & 10 & 1 \\
\hline Média geral & 3 & 8 & 8 & 9 & 2 & 6 & 2 \\
\hline
\end{tabular}

${ }^{1 /}$ Médias de tratamentos não diferem pelo teste $\mathrm{F}$ a $5 \%$ de probabilidade. 
de plantas daninhas na área, pode ocorrer que poucas gotas atinjam a superficie do solo, resultando em baixa eficiência do herbicida em préemergência, podendo tal situação ser agravada com a diminuição do volume de calda aplicado.

\section{LITERATURA CITADA}

CARVALHO, F. T.; CAVAZZANA, M. A. Eficácia de herbicidas no manejo de plantas daninhas para o plantio direto de soja. R. Bras. Herb., v. 1, p. 167-172, 2000.

CARVALHO, F. T. et al. Eficácia de herbicidas no manejo de Euphorbia heterophylla para o plantio direto de soja.

R. Bras. Herb., v. 1, p. 159-165, 2000.

CORRIGAN, K. A.; HARVEY, R. G. Glyphosate with and without residual herbicides in till soybean (Glycine max) production. Weed Technol., v. 14, p. 569-577, 2000.

KOGER, C. H.; REDDY, K. N. Glyphosate efficacy, absorption, and translocation in pitted morningglory (Ipomoea lacunosa). Weed Sci., v. 53, p. 277-283, 2005.

MONQUERO, P. A.; CHRISTOFFOLETI, P. J.; SANTOS, C. T. D. Glyphosate em mistura com herbicidas alternativos para o manejo de plantas daninhas. Planta Daninha, v. 19, p. 375-380, 2001.

NORSWORTHY, J. K.; GREY, T. L. Addition of nonionic surfactant to glyphosate plus chlorimuron. Weed Technol., v. 18, p. $588-593,2004$.
PROCÓPIO, S. O. et al. Efeitos de dessecantes no controle de plantas daninhas na cultura da soja. Planta Daninha, v. 24, p. 193-197, 2006.

ROMAN, E. S. Eficácia de herbicidas na dessecação e no controle residual de plantas daninhas no sistema desseque e plante. R. Bras. Herb., v. 3, p. 45-49, 2002.

ROMAN, E. S.; DIDONET, A. D. Controle de plantas daninhas no sistema de plantio direto de trigo e soja. Passo Fundo: EMBRAPA-CNPT, 1990. 32 p. (Circular Técnica, 2).

VALENTE, T. O.; CAVAZZANA, M. A. Efeito residual de chlorimuron-ethyl aplicado em mistura com glyphosate na dessecação de plantas daninhas. R. Bras. Herb., v. 1, p. 173-178, 2000.

VANGESSEL, M. J.; AYENI, A. A.; MAJEK, B. A. Glyphosate in full-season no-till glyphosate resistant soybean: role of preplant applications and residual herbicides. Weed Technol., v. 15, p. 714-724, 2001.

VANLIESHOUT, L. A.; LOUX, M. M. Interactions of glyphosate with residual herbicides in no-till soybean (Glycine max) production. Weed Technol., v. 14, p. 480-487, 2000.

VIDRINE, R. P.; GRIFFIN, J. L.; BLOUIN, D. C. Evaluation of reduced rates of glyphosate and chlorimuron in glyphosate-resistant soybean (Glycine max). Weed Technol., v. 16, p. 731-736, 2002. 